\title{
Identificações Coletivas e Gestão da Diversidade Étnico-Cultural: Dinâmicas Sociais Contrastantes entre Portugal e o Brasil
}

\section{Nuno Oliveira}

Centro de Investigação e Estudos de Sociologia (CIES) do Instituto Universitário de Lisboa. Lisboa, Portugal. E-mail: filicastrol@gmail.com

\section{CONSTRUÇÕES SOCIOSSIMBÓLICAS DAS IDENTIDADES COLETIVAS}

\begin{abstract}
A teoria social tem expendido diversas considerações sobre a importância da construção de fronteiras para a definição de um coletivo (Barth, 1976; Cohen, 1985; Lamont e Molnár, 2002). Estas abordagens têm por finalidade contrariar o essencialismo e a dimensão a-histórica subjacente a formulações tradicionais do conceito de identidade. Brubaker (2004:24) alertou recentemente para o uso excessivo da noção de identidade e o perigo de tornar indistintas todas as afiliações e pertenças, experiências de comunalidade e autoidentificações. Tanto Brubaker como a teoria das fronteiras simbólicas de Lamont colocam a tônica na dimensão processual, histórica e diacrônica das pertenças coletivas. O sentimento de pertença não dependeria apenas dos graus e formas de comunalidade: decorreria também de acontecimentos particulares, da sua codificação em narrativas públicas convincentes, e dos quadros discursivos prevalecentes. Se por um lado este repto convida a repensar o estudo das formações identitárias através das ferramentas da narrativa (Somers, 1994; Emirbayer, 1997; Sewell,1992), por outro, é de salientar que a construção das identidades coletivas não é meramente simbólica, sendo que as suas fronteiras devem ser institucionalizadas e legitimadas por vezes através de processos institucionais complexos, sendo certo que estas não possuem um referente, ou sustentáculo, exclusivamente simbólico ou retórico. Antes, elas são
\end{abstract}

DADOS - Revista de Ciências Sociais, Rio de Janeiro, vol. 58, no-4, 2015, pp. 1099 a 1130. 


\section{Nuno Oliveira}

o resultado de relações de poder e de forças distributivas cuja organização institucional engendra fronteiras coletivas e correspondentes sentimentos de solidariedade e confiança (Eisenstadt, 2003:75).

Dois conceitos que, quando conjugados, captam bem a interdependência destes fatores são os de identidade narrativa e de configuração relacional propostos por Somers $(1996 ; 1994)$. Da tipologia de narrativas que a autora sugere (Somers, 1994:619) aqui apenas destacaremos o conceito de narrativa pública, aquelas narrativas articuladas com formações culturais e institucionais para além do indivíduo, como redes de intersubjetividade e instituições situadas em escalas diversas (locais, macro etc.). O mais importante, no entanto, é notar que as narrativas não são incorporadas diretamente no $e u$, sendo antes mediadas através do enorme espectro de instituições sociais e políticas e das práticas que constituem o mundo social. Segue-se que a noção de configurações relacionais preenche conceitualmente o hiato heurístico entre pessoa e instituições. Somers define estas como "as relações padronizadas entre instituições, narrativas públicas e práticas sociais" (ibidem:626), e acrescenta que a formação da identidade é modelada dentro dessas configurações relacionais de encadeamentos contestados mas padronizados entre narrativas, pessoas e instituições. Uma configuração relacional tem sempre uma história, e por isso deve ser analisada tendo em conta a sua temporalidade e espacialidade. Sublinhe-se, porém, que os atores não são livres de escolher as narrativas que melhor se lhes adequem. Olastro histórico que estas possuem obriga a construir identificações e descrições do mundo dentro do acervo cultural e institucional existente num determinado tempo histórico. É neste sentido que o conceito de identidade narrativa é útil para desestabilizar a lógica essencialista da identidade categorial, colocando do mesmo passo o leque de narrativas identificatórias em relação com a construção institucional das fronteiras de um coletivo.

Neste artigo pretendo usar os conceitos de identidade narrativa e configuração relacional para compreender as diferentes formas como os Estados organizam os reconhecimentos coletivos e as suas gramáticas institucionais. A questão de saber como os Estados avaliam as identidades coletivas e que espaço lhes é outorgado na sua arquitetura institucional implica o problema de estarmos perante uma outra identidade coletiva, com pretensões homogeneizantes: a do próprio Estado-nação e do laço de cidadania que este estabelece enquanto categoria normativa e incorporadora. A este propósito, é consensual que a 
capacidade integrativa do Estado-nação encontra-se atualmente colocada em causa e que o princípio de cidadania que a sustinha é desafiado por fenômenos como os da cidadania pós-nacional (Soysal, 1994) ou transnacional (Bauböck, 1994). Em termos normativos, parafraseando Munch, estamos perante a questão de saber como os Estados-nação enfrentam os desafios da pluralização interna e da integração transnacional (2001:2). Em geral, para perceber as especificidades de cada Estado-nação na resolução desta equação, a maioria das propostas recorre a uma perspectiva histórico-genética que procura fundamentar estas diferenças nos primórdios da constituição dos Estados-nação (Munch, 2001; Brubaker, 1992).

Esta maneira de perspectivar os processos de construção da integração social cultiva uma especial incidência nos modelos de cidadania no sentido mais formal do termo, i.e., a condição propriamente estatutária e sua latitude legal. Podemos dizer que o que todas estas teorias partilham, na sua busca pela matriz original e passível de iluminar os processos de integração, é, primeiro, uma concepção trans-histórica da construção desses conceitos; segundo, a ideia de que pode ser estabelecida uma oposição formalística entre o ideal de cidadania incorporador e liberal e identidades coletivas comunitárias, das quais a resiliência da identidade nacional faria parte.

Comparar o Brasil e Portugal decorre em grande medida da ligação estabelecida pela narrativa lusotropical. Como procuraremos mostrar, esta narrativa é alvo de diversos graus de contestação, sobretudo no Brasil, enquanto em Portugal ela é assumidamente parte da esfera cívica. Este relato e suas mutações devem ser firmemente contextualizados seguindo o princípio proposto anteriormente de analisar a sua articulação com instituições e práticas sociais. Neste sentido, identificaremos e caracterizaremos várias configurações relacionais que respaldaram as pertenças coletivas ao longo da história recente. Do ponto de vista de uma história mais ortodoxa, tal ensejo envolveria um particular cuidado com a periodização. Por elementar que seja essa necessidade ao nível do ofício do historiador, o encadeamento entre narrativas públicas e instituições leva-nos apenas a recorrer a quadros amplos de tematização de períodos históricos. Propomos balizar esse período pela emergência do discurso lusotropical em Portugal e, no contexto brasileiro, a institucionalização da narrativa da mestiçagem. Quer o lusotropicalismo, quer o discurso cultural da mestiçagem, foram narrativas que fixaram as identidades nacionais de Portugal e Bra- 


\section{Nuno Oliveira}

sil, respectivamente, em boa parte do século XX, e ambos sofreram reconfigurações adaptativas das novas condições de cidadania na contemporaneidade destes dois contextos nacionais.

\section{PORTUGAL LUSOTROPICAL}

O pensamento colonial português do século XX é caracterizado pelas contradições e mutações que afetam o mito do excepcionalismo colonizador (Alexandre, 1993). Sobretudo a partir do segundo pós-guerra, a aproximação do modelo colonial português ao que se viria a consolidar como uma importação do lusotropicalismo freyriano na ideologia do Estado português e na sua política colonial configura uma modificação acentuada da narrativa pública que sustentava o império. A passagem de um imaginário imperial para uma ideologia ultramarina caracteriza essa transformação. Perante as acusações de colonialismo verberadas pelas instâncias internacionais contra Portugal, as elites políticas assumem a extensão simbólica de uma nacionalidade "plurirracial e multicontinental", que impedia retoricamente a ideia de descolonização, visto não existirem colônias, mas sim províncias que eram parte orgânica do país (Conceição Neto, 1997:341). Desta matriz identitária onde a grandeza imperial se confundiu por diversas vezes com um esforço de particularização em relação à Europa, participaram não apenas políticos do Estado Novo como também intelectuais, humanistas e acadêmicos (Matos, 2006).

Em diversas sedes, esta retórica é pronunciada como parte do esforço diplomático para reter os territórios coloniais (Nogueira, 1965). A terminologia do Ato Colonial de 1933 é considerada desajustada a uma época que não tolera mais a noção de Colônia. Assim, se no artigo 2 do Ato Colonial se afirma ser da "essência orgânica" da nação possuir e colonizar domínios ultramarinos, com a revisão da Constituição em 1951 a política do Estado Novo passa a designar-se "ultramarina", firmando um prolongamento jurídico-político cuja natureza administrativa era análoga à das províncias metropolitanas.

Esta "reorientação da política colonial numa política ultramarina" compreendia não só mudanças jurídico-administrativas, mas também uma assinalável transformação nos seus pressupostos ideológicos (Leonard, 1999:37). Referimo-nos como apontado pelo autor à importação de uma "vulgata lusotropicalista" que passou a codificar a relação institucional de Portugal com as colônias e os seus povos. As elites 
portuguesas adotam, com considerável grau de unanimidade, uma narrativa pública cuja pretensão era negar a prática propriamente colonial da época precedente. De um período onde o trabalho compulsivo, a cidadania diferenciada em virtude do Estatuto do Indigenato (que vigorou de 1926 a 1961) e a discriminação racial nas práticas cotidianas (Henriques, 2004; Conceição Neto, 1997; Castelo, 1998; Andrade, 1955) eram assumidos administrativamente, transita-se para a ideologia ecumênica da "unidade na diferença".

Do ajustamento das teorias de Freyre à negociação política portuguesa no pós-guerra, duas teses podem ser convocadas. Primeiro, uma que afirma a precedência de um campo cultural particularmente acolhedor para as teses de Freyre (Almeida, 2000:170). Seria justamente porque o pensamento etnogênico português continha in nuce os tropos do lusotropicalismo, que este foi facilmente transposto para a retórica política colonial em Portugal na segunda metade do século XX. A outra tese era a de que Freyre queria, na realidade, consumar uma hegemonia brasileira (Pinto, 2009:468). Esta põe em causa as versões que veem nas viagens de Freyre um apoio incondicional ao Estado Novo português e à doutrina salazarista de um Portugal do Minho a Timor. Com efeito, Freyre pretendia, segundo esta interpretação, apresentar a "civilização brasileira" como a única capaz de cumprir os desígnios lusotropicais encetados pelos portugueses. Se Portugal era o passado e o presente, o Brasil seria certamente o futuro ${ }^{1}$.

Descoincidência de tempos especulativos, que não deixa por isso de ser estrategicamente utilizada por Portugal. São sobejamente conhecidas as tentativas de apresentar o caso português nos fora internacional à luz do lusotropicalismo (Leonard, 1999; Castelo, 1998, 2007). A argumentação, por mais debatida que tenha sido, assentava na ideia de um caráter sui generis do colonialismo português, sendo frequente a invocação da "obra missionária" que lhe era supostamente imanente. Se esta ainda assim contém reverberações do cristianismo civilizador de grande parte da ideologia imperial, a insistência num caráter sincrético herdado dos portugueses e expandido num complexo civilizacional designado por "trópico" apresenta a sua novidade. A "interpenetração de raças e culturas é como que a criação de um tipo humano novo" ${ }^{2}$, diria o então ministro do Ultramar, professor Adriano Moreira, ecoando a ideia do homem metarracial de Freyre, figura que, ignorante do "preconceito rácico" e tolerante no seu universalismo missionário, desloca 


\section{Nuno Oliveira}

o discurso do caráter civilizador da ordem imperial para a multirracialidade.

Esta forma como o intercâmbio entre Portugal e Brasil é realizado apela com efeito a uma dinâmica bipolarizada de reforços identitários, na qual o Brasil surge por diversas ocasiões como nação de referência. Marcelo Caetano utilizará o exemplo brasileiro para justificar o putativo sucesso e excepcionalidade do trabalho de colonização português ${ }^{3}$. Franco Nogueira, enquanto ministro dos Negócios Estrangeiros de Salazar, irá usar o termo "democracia racial" para caracterizar a administração portuguesa do Ultramar durante um discurso proferido perante o Conselho de Segurança da Organização das Nações Unidas (ONU) em $1963^{4}$.

No plano institucional, assiste-se a um esforço deliberado de doutrinação dos funcionários da administração estatal no lusotropicalismo (Castelo, 2011; Conceição Neto, 1997). Sarmento Rodrigues e Adriano Moreira serão os responsáveis mais proeminentes pela institucionalização do lusotropicalismo no esforço de reforma do regime colonial do pós-guerra (Pinto, 2009). Nos seus testemunhos, a invenção de um homem cordial, sem preconceito racial, fundador de uma sociedade multirracial como esteio para uma nova civilização está presente como uma marca indelével da empresa colonial portuguesa.

Não obstante, a perspectiva que vê uma mudança radical nas apropriações de Freyre por parte das elites intelectuais e administrativas portuguesas tende a negligenciar que, a haver uma transição semântica, a substância desta retórica mantém-se singularmente nacionalista. A estrutura simbólica que percorre os dois períodos é a do nacionalismo, e esta, quer seja nas suas declinações abertamente imperialistas, quer humanistas, escora-se num nacionalismo patriótico que perpassa tanto pelas contumazes afirmações de orgulho pátrio nas palavras de Armindo Monteiro e Salazar como pelos trabalhos de putativo fundo mais científico que encontramos nas publicações do Centro de Estudos Políticos e Sociais (CEPS) da Junta de Investigações do Ultramar (JIU) ${ }^{5}$. Em resumo, um ajustamento às condições internacionais de uma retórica abertamente imperialista com apropriação instrumental da teoria lusotropical de Freyre, mas que, ao contrário desta, enaltece o nacionalismo português, enquanto a última é uma elaboração científica sustentadora do nacionalismo brasileiro e por este assim apreendida. Em verdade, a questão da mestiçagem, que tem uma importância central 
em Freyre para explicar o Brasil, pouco relevo possui nos teóricos portugueses do excepcionalismo luso. Se a ideia da excepcionalidade da "missão" portuguesa era pacífica numa fase inicial da colonização de Angola e Moçambique, a ênfase na miscigenação já era considerada descabida por pessoas como o comandante Ernesto de Vilhena, Norton de Matos ou mesmo Marcelo Caetano, que não encaravam a miscigenação como um projeto interessante para o futuro colonial português (Castelo, 1998:94-95).

O regime adota a linguagem da multirracialidade, operando assim o deslocamento do termo "raça" para um espaço moral, não enfatizando nunca a ideia de mestiçagem e a sua putativa lógica social. Anação pluricontinental que emergia da Constituição de 1951 pretendia construir uma hiperidentificação entre portugueses de todas as raças, como ilustra o título da obra de António de Andrade (1968), Muitas Raças, uma só Nação. A retórica da plurirracialidade sustenta-se em dois pressupostos. Primeiro, uma vertente legalista, que é aquela que podemos encontrar na diplomacia portuguesa a partir da entrada do país na ONU, em 1956. Esta enfatiza a igualdade formal entre metrópole e territórios ultramarinos, assim como a sujeição de toda a população aos mesmos princípios legais. Segundo, se em alguma coisa seria encontrada uma justificativa para atribuir um grau de excepcionalidade ao colonialismo português, essa seria a inexistência da divisão cromática ${ }^{6}$.

Ora, estas declarações eram feitas num contexto que, embora mostrasse sinais de abertura a lógicas de unificação nacionalista, herdara um sistema administrativo e político em que a cor figurava com proeminência assinalável. Esta divisão tinha sido instrumental para uma cidadania diferenciada ao abrigo do Estatuto do Indigenato que separava administrativamente os civilizados, com direitos de plena cidadania, dos “indígenas". Desde logo porque a definição de indígena era bastante explícita no que diz respeito ao fenótipo: nativos eram todos aqueles de cor preta ou os seus descendentes.

Esta clivagem cultural e simbólica entre a linguagem da unificação nacional (própria do Estado-nação) e o resultado estrutural da divisão e multiplicação de estatutos - ou, na acepção de Cooper (2005), o governo diferenciado de povos diferentes ${ }^{7}$ (própria do Estado-império) caracteriza amplamente a cultura imperial portuguesa neste período. Se este binômio, ou ambiguidade, se encontra subjacente a qualquer projeto de construção nacional sustentado na expansão imperial, como 


\section{Nuno Oliveira}

sugere Cooper, no Portugal do pós-guerra ele é particularmente agudizado desde logo porque sistematiza uma ideologia da integração (assimilação) que pretende rasurar os efeitos estruturais da dominação imperial. Uma retórica integracionista segundo a qual "todos os grupos étnicos [estariam] estreitamente integrados e ligados entre si por um profundo sentimento de unidade" (Nogueira, 1965:49) assume o estatuto de representação coletiva para as elites nacionais do último período colonial.

\section{BRASIL MESTIÇO OU DESIGUAL?}

Em matéria de identidades coletivas, o Brasil adotou, enquanto simbolismo da comunidade imaginada, um paradigma da mestiçagem, de ordem que a ideologia da mestiçagem servirá de trave mestra para a construção do projeto de unidade nacional, sendo absorvida e instrumentalizada pelo Estado corporativista e vigorando como discurso oficial até a entrada dos anos 1990, quando começa a ser contestada (Costa, 2006; Guimarães, 2009). A categoria de mestiço impregna o imaginário cultural e artístico brasileiro, com reverberações políticas estruturantes das relações entre os diversos grupos sociais em presença na sociedade brasileira (Freyre, 2004; Ribeiro, 1995). Em certa medida, equivale àquilo a que Santos (2009:15) se refere como sendo um topoi da cultura ${ }^{8}$. Entre a ideia de mestiçagem e a de identidade nacional, existe uma continuidade simbólica que circunscreve a narrativa da segunda. Não significa que suas premissas não tenham sido alguma vez contestadas, mesmo quando este assumia o caráter de paradigma dominante nos exercícios de autognose das elites brasileiras.

Sucede, contudo, que a sua autodefinição era indissociável de um sentimento de unidade nacional, e nesse sentido os limites hermenêuticos da categoria mestiço oscilaram sempre entre o cultural e o político. Como seu eixo, a diluição de fronteiras identitárias (em boa verdade étnico-raciais) consumada através daquela figura prototípica enunciada por Freyre do homem metarracial. A história da escravatura e da dominação racial que caracterizou o Brasil Império (Cardoso, 1962; Degler, 1971; Gorender, 1988; Costa, 1966; Mattos, 2000) mostrou uma face dupla entre a unidade idealizada e as fraturas raciais que não suturaram mesmo depois do advento da Primeira República e do Brasil moderno (Russell-Wood, 1982; Schwarcz, 1993; Skidmore, 1989). Entre o projeto de modernização do Brasil e a elevação política e nacional da categoria de cidadão intrometiam-se persistentes clivagens sociais, de 
classe e raciais. A consciência desse fato estava bem presente nas interpretações das elites intelectuais. Por isso, compreende-se que o que para uns tinha uma solução biogenética e cultural (Freyre, 1950, 2004) adquiria, para outros, contornos estruturais e classistas (Fernandes, 1965; Ianni, 1972). Não obstante, dentro do paradigma de unificação nacional que tinha por operador simbólico a mestiçagem, elas eram suficientemente incompatíveis para apenas uma expressar mais fielmente - com a fidelidade da articulação dos interesses políticos e hegemônicos - o caráter brasileiro. Não se pense no entanto que este "caráter" foi algo de imanente ao qual não presidiu o trabalho institucional de elaboração e reprodução. O estadonovismo apropria-se das teses de Freyre para construir a sua simbólica de unidade nacional que irá disseminar pelos seus aparelhos de propaganda cultural, como o Departamento de Imprensa e Propaganda (DIP) ou através do Ministério da Educação e da Saúde (Gomes, 1997; Hentschke, 2006). O ajustamento destas teses ao programa nacionalista e centralizador de Vargas será mais tarde criticado pelo próprio Freyre (1945:87).

No entanto, a leitura feita pelo Estado Novo da democracia étnica propalada pela obra de Freyre até a data se insere na lógica da construção de uma sociedade horizontalizada por um traço comum, em que a harmonia destacada na sua obra de 1933 é transposta para um programa de inculcação de uma sociedade sem clivagens sociais, unida sob um desígnio comum. A visão ecológica do Brasil e do seu povo, assim como exposta por Freyre, conhece a sua tradução política na propaganda nacionalista em torno da democracia racial. O "povo brasileiro", caracterizado na sua singularidade como uma "raça de mestiços", faz parte de uma ideologia unificadora que atribui à figura do mestiço um conteúdo moral, político e social (Gomes, 1997) que reformula a identidade nacional brasileira, positivando-a através dos seus elementos raciológicos. Freyre surge destacado nesta atribuição de um lugar moral do mestiço no desenrolar histórico e progresso social brasileiro. Na esteira de homens como Roquette-Pinto e Oliveira Lima, para quem a identidade brasileira teria que ser recriada para além das teses do branqueamento e da degeneração racial $^{9}$, o fusionismo concebido por Freyre à luz destes princípios quadrava bem com a procura de unidade política e social.

Apesar de o autor não estar alinhado com as posições do Estado Novo, podemos identificar uma afinidade eletiva entre o programa de unidade cultural e étnica defendido por Freyre e o projeto de unificação polí- 


\section{Nuno Oliveira}

tica conduzido pelo varguismo e os seus aparelhos ideológicos. Se é certo que, como diz Araújo (1994), a obra de Freyre introduzia elevado ao estatuto de método a articulação dos contrários, é certo também que estes sempre se fundem, nunca resultando em relações dialéticas. $\mathrm{O}$ "fusionismo" de Freyre não cria híbridos na acepção mais ecológica do termo: gera, sim, entidades organicamente integradas. Como matriz de um pensamento nacional, esta interpretação condensava, entre outras, duas noções estruturantes da diversidade racial brasileira. Ao pensamento modernizador onde o regime conservador de Vargas alicerçava a sua visão progressista de um Brasil contemporâneo e industrial associava-se uma retórica populista que perspectivava a sociedade brasileira enquanto um todo sem fraturas, quer estas fossem de classe, quer racializadas, forjado segundo um "pacto nacional-desenvolvimentista" no qual os negros brasileiros teriam sido inteiramente integrados à nação brasileira, em termos simbólicos, através da adoção de uma cultura nacional mestiça ou sincrética (Guimarães, 2003:166). A prestação de Freyre é, a este título, menos de elaboração de uma ideologia nacionalista e mais de uma sequência de teses que se sustentam em premissas essencialistas. As sistemáticas caracterizações dos grupos que vão se sucedendo nas suas múltiplas observações revestem-se de ilustrações, quer do caráter psicológico, quer grupal, vincadamente essencialistas. Não é apenas que a ideia de raça surja destacada ${ }^{10},{ }$ contrariando aqueles que apontam a sua novidade culturalista; é a continuidade entre uma ecologia e a ação e os comportamentos humanos que está tão presente em Freyre, como numa inesgotável ordem de essências. É assim que a democracia étnica é algo que já se encontra em prática pela acomodação quase ótima que os portugueses têm aos trópicos (Freyre, 1945:27). E digo quase porque existem fatores sociais e políticos - tais como o jesuitismo - que impedem que a ordem dos elementos (das essências) se conjugue para uma solução ótima. A democracia étnica não é, assim, um sistema político, mas antes, a constatação histórica de inexistência de preconceito racial no Brasil desde os seus primórdios.

O próprio papel de Freyre é ambivalente na construção desta caracterologia. Por um lado - sobretudo na sua obra mais emblemática -, afirma-se como querendo contrariar o racismo explícito, eugênico, de grande parte da produção intelectual e científica anterior aos anos 1930, reelaborando o Brasil na sua positividade de nação que melhor combinou as suas múltiplas raízes. Por outro lado, é inegável que a sua lusotropicalogia daí decorrente cauciona um programa político, exten- 
sível em reelaborações das suas premissas do outro lado do Atlântico na forma como sofreu diversas adaptações pelas elites portuguesas embebendo as concepções ideológicas do império ultramarino e dando-lhe um sustentáculo ideológico precioso no concurso da política internacional (Medina, 2000; Leonard, 1999; Alexandre, 1993, 1998). No Brasil, levaria, por exemplo, Octávio Ianni a afirmar, no seu marxismo insofismável, que o mito da "democracia racial" não faria mais do que encobrir a desigualdade gerada pela discriminação de que eram alvo negros e mulatos (Ianni, 1972:15). Ora, esta era uma interpretação do Brasil em confronto com a ideia de combinação entre gênese etnocultural e unidade política. Em síntese, com a brevidade interpretativa que este espaço me permite, o tema de uma sociedade unida cultural e geneticamente embatia nas disputas acadêmicas e políticas com a observação de uma sociedade fraturada, cuja clivagem corresponderia à cor da pele. Afinal, a suposta plasticidade etnogênica brasileira não era suficiente para garantir a unidade política.

Embora este discurso tenha obtido os seus porta-vozes dentro da academia desde a década de 1950, como provam os estudos da escola paulista e dos brasilianistas norte-americanos, só perto da década de 1980 do século XX é que ele ganha alguma materialização na esfera do Estado. Esta transição é importante porque é aqui que se começa a redefinir uma nova organização social das identificações coletivas com evidentes impactos na narrativa nacional. Posto que, como dito anteriormente, um dos topoi desta narrativa era a inevitabilidade da fusão, do encontro dos contrários, da miscigenação e do sincretismo, a saliência da fratura social e da diferença de cor eleva-se ao estatuto de contranarrativa identitária. Desde logo, porque passamos de um entendimento "fusionista" da totalidade societal para a observação das suas contradições internas. Isso equivale a uma redefinição da narrativa da identidade nacional, versão concorrente que se elabora em torno da narrativa de um país dividido e desigual racialmente. Para isso a identificação de uma categoria numa posição social desvantajosa foi instrumental. Sucede que, se a unidade do projeto "assimilador" decorria de um processo ecológico de amálgama obtido sem a intervenção do Estado (Thomaz, 2007:57), a partir da década de 1980 o Estado torna-se um ator estratégico na prossecução dessa intenção, mas segundo princípios inteiramente diferentes, que prefiguram lógicas institucionais multiculturalistas. 


\section{Nuno Oliveira}

\section{A DESETNIZAÇÃO PORTUGUESA}

Consideremos a racialização como um caso particular de etnicização, ou seja, quando as fronteiras entre os grupos étnicos forem compreendidas em termos raciais ou racializantes.

No caso português, e situando-nos no período conturbado da descolonização, o quadro que serviu de referência para a incorporação de imigrantes e populações pós-coloniais no Portugal democrático definia a situação através da relação histórica de uma comunidade imaginada que unia o império e que é, em larga medida, transplantada para a organização institucional e simbólica nos primórdios da imigração para Portugal, concretamente no final da década de 1980 e início da de 1990. O fato de haver um ajustamento entre a estrutura cultural e a realidade dos fluxos migratórios, dado que estes eram majoritariamente provenientes do ex-ultramar africano, permitiu que esta transição fosse feita sem grandes sobressaltos institucionais, implicando as antigas soluções em matéria de institucionalização e da narrativa que organizava o seu significado. Este era, em parte, devedor da ideologia do lusotropicalismo, que, embora sujeita a críticas em certos círculos políticos, sustentou ainda assim as principais posturas políticas desta época, como podemos constatar pelos discursos dos parlamentares em ocasiões de discussão de assuntos conexos com a imigração (Oliveira, 2001, 2012). Com efeito, a extensão ideológica da retórica lusotropical faz-se presente nas reivindicações de uma afinidade histórica que serviria de matriz cultural ininterrompida, transversal aos acontecimentos concretos de uma relação imperial, mesmo com as lacunas e dificuldades inerentes a um país periférico como Portugal. Neste quadro, contrariamente a outros exemplos europeus, tais como a Inglaterra ou a Holan$\mathrm{da}$, as questões associadas à integração das populações imigrantes dos Países Africanos de Língua Oficial Portuguesa (Palop) não foram equacionadas tendo por eixo a discriminação ou a desigualdade racial e étnica.

É assim que aos programas de combate à discriminação como o Racial Act britânico, ou a definição de minoria étnica correspondendo à situação estrutural dos grupos imigrantes na Holanda - com as consequentes medidas sociais -, sucede em Portugal uma busca pelo aprofundamento da cidadania universal mediante a extensão do enquadramento legal, sustentada numa codificação da integração social que representa a sociedade portuguesa como intrinsecamente híbrida, 
apelativa ao sincretismo cultural e étnico. De acordo com Pires (2003:243), a matriz desse modelo seria proveniente do período pós-descolonização, durante o qual Portugal recebeu um influxo de mais de 500.000 indivíduos. A intervenção estratégica do Estado em vários domínios teria evitado pragmaticamente quer a coletivização dos direitos através da individualização "contratual" prosseguida pelos diversos apoios formais, quer a lógica de "negociação coletiva de integração" ao gerir a situação de "retornado" enquanto categoria transitória, rejeitando medidas compagináveis com a discriminação positiva.

Esta faceta legal e política teve implicações na criação de estruturas de oportunidade para as populações de imigrantes. Desde logo, a ambiguidade de um quadro institucional que assume o conceito de minorias étnicas, consubstanciado no estabelecimento de um alto comissário para a Imigração e Minorias Étnicas, sem qualquer respaldo legal que definisse e legitimasse esse mesmo conceito. Pelo contrário, quer o conceito quer uma sua possível institucionalização foram sendo rejeitados. No início da década de 1990, o então alto comissário alertava para os perigos da "positivização da etnicidade", recusando a legitimação de identificações étnicas fortes. Subjacente a este repto encontrava-se uma recusa de posturas na esfera pública mediadas por significados racializados. Por conseguinte, a um quadro institucional que admitia nominalmente a existência de minorias étnicas, não correspondia nenhuma definição legítima nem qualquer codificação que autodefinisse (e assim fazendo circunscrevesse o seu âmbito para o exterior) uma minoria étnica, de forma que a ambiguidade na identificação destes coletivos aflora desde cedo nos discursos e sistemas de classificação estatais.

Uma primeira tentativa de atribuição de identificações étnicas pode ser encontrada na recolha de dados efetuada aos alunos das escolas do primeiro e segundo ciclo (segundo o sistema classificativo atual) pelo Secretariado Coordenador dos Programas de Educação Multicultural. Muito embora estas nunca fossem estritamente definidas, sendo o seu caráter mais alusivo do que identificatório, é neste processo que se tentam as primeiras e únicas categorias étnico-culturais oficializadas e organizadas centralmente. Os alunos eram divididos em grupos "culturais", embora de contornos difusos - como prova a inclusão de um grupo de filhos de emigrantes -, que compreendiam categorias como Africano do Palop, União Europeia, Asiáticos, Ex-emigrantes, Brasileiros e 


\section{Nuno Oliveira}

Ciganos, recusando sempre inscrever significados raciais. Revestiu-se esta experiência de um caráter exo-classificatório onde as categorias eram impostas pelo próprio organismo que as oficializou. A autoidentificação nunca foi experimentada pela administração em registros oficiais. Estes registros foram descontinuados em 2004 por se tratar de "informações sensíveis"11.

Assim, tão cedo quanto no início da década de 1990, o ministro da Educação Roberto Carneiro (1997:80) invocava o fim da "homogeneização cultural e [da] assimilação", sugerindo a "passagem da cultura à multicultura" operada pela e na educação intercultural. A erosão crítica do multiculturalismo ainda não se tinha constituído enquanto necessidade de repensar os seus pressupostos e implicações sociais. A linguagem programática da interculturalidade decorria, em rigor, de uma autodefinição do sistema educativo enquanto sistema em progressiva e necessária democratização ${ }^{12}$ - o discurso da escola para todos (Leite, 2002:288) - e menos da incorporação da linguagem das identidades no Estado.

Paralelamente, com a extensão dos direitos dos imigrantes nas diversas esferas sociais, e o consequente alargamento da sua cidadania, a institucionalização das estruturas de oportunidade e discursivas revestia-se também de aspectos peculiares. No início do século XXI emerge, paradoxalmente, um discurso defensor do multiculturalismo por parte do órgão central responsável pela política de integração, o alto comissário ${ }^{13}$. Neste sentido, este discurso sinaliza o autoentendimento que o sistema político produz sobre si próprio no que se refere à acomodação da diversidade no espaço social e legal nacional. Porém, o discurso encomiástico sobre o multiculturalismo não é codificado de acordo com uma redefinição das autoconcepções do sistema, de forma que esta breve aparição da defesa do multiculturalismo como paradigma da gestão da diversidade nacional é rapidamente ajustada à preferência pela interculturalidade dimanada pelo Conselho da Europa. Na declaração de Faro de 2005 sobre diálogo intercultural que servirá de base para o White Paper de $2008^{14}$, suprimiu-se o termo minorias étnicas e este processo de ressemantização foi institucionalmente prosseguido, como pode ser verificado pelas declarações proferidas na sede do Conselho Consultivo para a Imigração.

Este redirecionamento na gestão da diversidade é igualmente anunciado no livro do alto comissário Uma Mesa com Lugar para Todos: Para uma Visão Humanista da Imigração, de 2005, e aparecerá mais tarde no Plano 
de Integração de Imigrantes como modelo orientador. A interculturalidade assume-se enquanto discurso a privilegiar por parte das autoridades públicas, obedecendo a uma progressiva recusa de identificações étnicas fortes. A ideia de existência de minorias étnicas face uma maioria é rejeitada em favor de um intercâmbio permanente entre sociedade de acolhimento e comunidades imigrantes. Este intercâmbio encontra o seu respaldo no domínio cultural, dimensão transversal por excelência ao contacto e trocas entre os diversos "povos". Ao nível discursivo o interculturalismo era assim definido: "Aceitação da especificidade cultural das diferentes comunidades equacionada com o carácter relacional e interativo das mesmas, num quadro de respeito mútuo e de cumprimento das leis do país", em declaração do alto comissário, de acordo com a versão acolhida pelo I Plano de Integração de Imigrantes $^{15}$. Esta concepção esvaziava a dicotomia (hierarquizante) minoria/maioria. Pela mesma ordem de ideias uma política de reconhecimento torna-se inócua, dado que indivíduos e grupos se encontram em igualdade de circunstâncias numa relação de mútua compreensão.

A assunção do interculturalismo como paradigma de gestão da diversidade surge patente nos dois decretos que dão origem aos respectivos planos de integração de imigrantes sob a formulação de diálogo intercultural. Este modelo ficaria assim inscrito na lei, sendo que no panorama europeu apenas a Bélgica e a Espanha possuíam tais referências na legislação, e ambas decorrentes do reconhecimento estatutário das suas minorias nacionais. Esta assunção não introduziu problemas no espectro político nacional. Existe um consenso entre a quase totalidade das forças políticas e religiosas - à exceção de um partido radical de direita, o Partido Nacional Renovador (PNR), sem expressão parlamentar - sobre as virtudes de uma sociedade na qual as comunidades imigrantes possam expressar livremente a sua cultura e onde as diferenças entre os grupos, quando existem, sejam reduzidas aos seus aspectos culturalizados. Todavia, o discurso da integração não incide nos tópicos e exigências culturalistas de pendor assimilacionista como nos contextos francês (Fassin e Simon, 2008), ou holandês (Uitermark, 2012). Pelo contrário, ele releva as dinâmicas de interpenetração simbólica, os intercâmbios entre sociedade de acolhimento e comunidades imigrantes, e a natureza plástica destas relações. Este discurso é homogeneamente partilhado quer seja por instituições estatais, quer por organizações da sociedade civil, salvo uma tendência emergente numa terceira geração de descendentes de africanos que reformula este consenso em termos do lugar estrutural da raça e dos seus impactos em 


\section{Nuno Oliveira}

oportunidades desiguais. Mas esta não constitui a narrativa pública, tratando-se antes de uma contranarrativa residual difundida através de expressões artísticas e estéticas.

\section{O MULTICULTURALISMO COMO PROJETO SOCIAL}

Apraz dizer antes algo que será desenvolvido seguidamente: o multiculturalismo no Brasil surge como um projeto social na última vintena do século XX. Tal fato não é de somenos, na medida em que não é entendido como uma filosofia política de construção da "boa sociedade", tampouco como um multiculturalismo tradicional anglo-saxônico de acomodação da diferença cultural no espaço político liberal. Neste preciso sentido designaremos aquilo que se observa no Brasil como um movimento da culturalização para a equidade, por oposição à conjuntura portuguesa - extensível ao espaço europeu, em nossa opinião onde identificamos a tendência inversa, ou seja, o deslocamento dos elementos ligados à desigualdade para aspectos culturalizadores.

A tendência brasileira decorre da dinâmica de consolidação de políticas orientadas para o combate à discriminação racial que têm por base um reconhecimento simbólico e prático da importância da raça como critério quer de direitos, quer de exclusão. Este processo, com a respectiva institucionalização, marca uma inflexão no paradigma do hibridismo que sustentava a "democracia racial" em direção a um multiculturalismo de gênese político-estatal que oferece um espaço de representação à população negra, reelaborando do mesmo passo as narrativas da identidade nacional. Em matéria de oportunidades institucionais, uma sequência de medidas no quadro do reconhecimento podem aqui ser elencadas, desde a inscrição na Constituição de 1988 de uma população negra objeto de políticas de discriminação positiva até a implementação de cotas para negros no ensino superior, medida que foi alvo de contestação por parte de diversos setores da sociedade, entre eles o Democratas (DEM), partido que entregou uma ação de contestação no Supremo Tribunal - que mais tarde, viria a considerá-la improcedente. Em outro trabalho, escalpelizei o processo de emergência destas políticas e a sua posterior institucionalização (Oliveira, 2012). Destas podemos salientar, sem a preocupação de sermos exaustivos, a reaproximação do ativismo negro ao Estado resultante do suporte institucional da criação dos órgãos de Igualdade de Promoção Racial (PIR), no âmbito do Sinapir (Sistema Nacional de Promoção da Igualdade Racial), que vai desde a Secretaria de Políticas de Promoção da 
Igualdade Racial (Sepir), a instituição coordenadora, às secretarias estaduais, distritais e municipais. Outra das vias foi o reconhecimento de uma população hifenizada (prefixo cultural e histórico afro ou negro) através da inclusão, na rede oficial de ensino, da obrigatoriedade do ensino da História e Cultura Afro-brasileira e da África (Lei 10.639 de 9/1/2003).

A preocupação com o lugar estrutural da população negra ganha relevo no Programa Plurianual do governo PT (Partido dos Trabalhadores) ao nele inscrever a "superação das desigualdades raciais". Mas mais elaborado, e de maior alcance, é o Programa de Direitos Humanos de 2009, aprofundando a linha inaugurada pelo governo Fernando Henrique Cardoso. É desta forma que no III Programa de Direitos Humanos de 2010 no capítulo dedicado às propostas governamentais, é-nos dado observar, no excerto dedicado às medidas de curto prazo, a "Inclusão do quesito 'cor' em todos e quaisquer sistemas de informação e registro sobre a população e bancos de dados públicos" (alínea 9); enquanto medidas de médio prazo, de acordo com as alíneas 138, 141, 142 e 144, entre outras, preveem a criação de um "banco de dados sobre a situação dos direitos civis, políticos, sociais, econômicos e culturais da população negra na sociedade brasileira que oriente políticas afirmativas visando a promoção dessa comunidade" (alínea 138), o aprofundamento da ação afirmativa nos cursos profissionalizantes, na universidade e nas áreas de tecnologia de ponta (alínea 141), a ênfase nos manuais didáticos da "história e as lutas do povo negro na construção do nosso país, eliminando estereótipos e discriminações" (alínea 144), e finalmente, a orientação para o Instituto Brasileiro de Geografia e Estatística (IBGE) considerar "os mulatos, os pardos e os pretos como integrantes do contingente da população negra" (alínea 144) ${ }^{16}$.

Um dos aspectos que importa salientar foi como a institucionalização destas políticas se fez em paralelo com a construção social da categoria negro. Em termos estatísticos e censitários, esta construção implicou a junção de duas categorias de cor típicas dos mecanismos de recolha de informação estatais sobre as populações; o que no sistema de classificação de cores brasileiro corresponde ao pardo e preto. Implicou por conseguinte a absorção - social e política - do termo intermédio, pardo, na categoria negro. O impacto nos critérios simbólicos de construção da identidade coletiva - quer no âmbito do espaço nacional, quer na sua dimensão grupal - não sendo determinante, possui pelo menos algum relevo na estrutura normativa da sociedade brasileira, na medi- 


\section{Nuno Oliveira}

da em que a "narrativa da vocação brasileira para hibridizar" é contestada por narrativas concorrentes que colocam a desigualdade e a divisão no centro da comunidade imaginada (Costa, 2006:133). Em termos culturais passamos do topoi da sociedade sincrética para a sociedade fraturada, desta feita entre negros e brancos.

É também neste quadro que as alusões ao multiculturalismo norteamericano ganham toda a sua dimensão. Tendo por certo que a "vocação" brasileira foi contraposta à desigualdade norte-americana, sobretudo em Freyre, a institucionalização de uma matriz que reconhece dois grandes grupos nominais - os negros e os brancos - aproxima o Brasil do multiculturalismo norte-americano assim como ele foi concebido dentro do sistema de relações raciais. É que se Freyre pôde dizer em Sobrados e Mucambos que "o problema do negro está simplificado pela miscigenação larga" (2004:362), as novas disposições legais, em formato de políticas de ação afirmativa, recuperam o problema do negro desta feita sob o prisma estrutural. A polêmica gerada em torno das cotas para negros nas universidades e em outros setores, mais do que refletir a bondade do sistema redistributivo que esta medida implica, trouxe no seu bojo uma requalificação da cidadania liberal nos termos tradicionais e modernos em que esta era equacionada.

Assim, temos que, menos que uma oposição entre codificações primordiais e cívicas, as configurações institucionais do Brasil contemporâneo convidam a pensar a indispensabilidade da definição de fronteiras entre coletivos, ou, como queria Eisenstadt (2003), a condição da reconstrução contínua da primordialidade. O negro existia, obviamente, não sendo uma abstração; existia declinado como preto ou pardo, ambas as classificações servindo como categorias sinalizadoras de uma hierarquia social da cor. A forma como essa hierarquia foi construída não é tema deste texto, nem tampouco as suas mutações históricas. $O$ que é relevante, quanto a nós, é o negro enquanto categoria política; ao limite, chega mesmo a ser uma categoria biopolítica, no sentido em que inscreve e regula uma população construindo novas subjetividades reforçadas pelo saber recolhido através de dispositivos técnicos que lhe dão a visibilidade e a integram numa compreensão alternativa da sociedade brasileira.

Ou seja, neste processo de reinterpretação da narrativa nacional, a categoria negro e a sua formulação em políticas públicas é central, ganhando subsequentemente uma dinâmica própria que produz uma 
"voz" no espaço público brasileiro. Ora, esta categoria sustenta-se simbólica e culturalmente em algo que foi por diversas vezes negado pelas análises freyrianas da gênese étnico-cultural do Brasil. Refiro-me à consciência negra, ou consciência de ser negro, o que para Freyre era uma impossibilidade num caldo cultural e genésico de miscigenação. O lado de transformação política exercido pela ação do poder simbólico sobre uma categoria demográfica declinado pelo Movimento Negro como fórmula unitária de reivindicação de um novo lugar na hierarquia social da cor possui como coadjuvante a admissão de uma diferença material: a desigualdade racial, a discriminação em diversas esferas sociais, as desvantagens objetivas de ser negro.

A positivização do negro não é uma novidade: Freyre e os fusionistas muito fizeram nesse sentido, só que sempre no interior do molde nacional, ou nacionalista, o que implicava um reconhecimento consoante a bitola de um Brasil branco. A novidade das novas configurações encontra-se no fato de estas impelirem uma solução integrativa que não passe apenas pelos recursos culturais e pelo projeto "natural", mas sim por uma verdadeira política social no sentido em que os recursos a serem distribuídos possuem um caráter material efetivo. É o respaldo institucional que dá visibilidade a essa reconfiguração identitária, que permite legitimar a contranarrativa. Sem o suporte do Estado ela dificilmente ganharia a força efetiva que tem granjeado.

\section{Portugal Intercultural: Uma Abordagem Simbólico-Estrutural}

O caso português pode levar a pensar que se trata de uma solução cívica em que o indivíduo possui a primazia sobre o coletivo. Na realidade é apenas uma outra forma de gerir a primordialidade, contendo e atenuando as manifestações de um coletivismo mais elaborado, mas reforçando a normatividade central de um coletivismo nacional institucionalmente legitimado. Esta autodefinição nacional tem consequências no plano das definições coletivas que podem se manifestar dentro do seu território.

Dando-se o caso de a definição oficial ser partilhada pela grande maioria dos atores envolvidos no campo das políticas de integração, compreendendo-se aqui as associações de imigrantes e outros atores associativos e estatais, tais como as organizações antirracistas ou da Igreja Católica, não devemos, contudo, negligenciar os elementos estruturais no estabelecimento do modelo intercultural. Em particular, a estraté- 


\section{Nuno Oliveira}

gia de centralização pelo Estado. Esta deve ser analisada enquanto função latente do discurso da coesão social e evitamento da fragmentação societal por identidades concorrentes.

Ao nível central, o Conselho Consultivo para os Assuntos da Imigração (COCAI) dir-se-ia ser a entidade mais suscetível de influenciar a política estatal, sendo o órgão colegial no qual se encontram representadas as comunidades imigrantes cujos membros são escolhidos por eleições internas e que são chamados a se pronunciar periodicamente a respeito de assuntos relativos à integração de imigrantes. A esta estrutura de representação do tecido associativo migratório deve-se acrescentar a rede de CLAIs (Centro Local de Apoio aos Imigrantes), ascendendo a um número superior a 100, disseminados por todo o país. Estas duas estruturas, aparentemente favoráveis à expressão pública das comunidades de grupos imigrantes esvaziam no entanto a ação política do tecido associativo estabelecendo com este uma relação de dependência entre poder central e os seus representantes.

Ora, este modelo implica um alinhamento entre a vontade do Estado e a das organizações comunitárias. Na realidade, não impede uma comunitarização das populações imigrantes, mas força-a ao molde nacional de construção de um coletivo e das suas narrativas. É neste sentido que as definições centrais de comunidade cívica e o seu discurso integrador se ajustam às identidades periféricas dos grupos que gravitam em torno das estruturas de oportunidade estatais. O discurso que presidiu este ajustamento se constrói sob o domínio da interculturalidade. A uma tal concepção de cultura - dado que o que se encontra subjacente é um entendimento particular da cultura - opor-se-á uma noção de cultura essencializada que podemos porventura encontrar nas políticas de identidade. Se a rejeição da essencialização parece estar presente no vocabulário da interculturalidade, esta faz-se em estreita articulação com o Estado. Com efeito, em nenhuma instância surge uma etnicidade competitiva, segundo a noção de Pieterse (2007:115), a qual envolve "competição com o Estado ou outras formações culturais relativamente ao poder estatal, recursos e desenvolvimento". Uma ausência que corrobora inteiramente este diagnóstico pode ser notada na recusa quer por parte dos representantes associativos, quer dos atores estatais em equacionar a monitorização étnica ou medidas de ação positiva $^{17}$.

Segundo, o repertório usado quer pelos atores associativos quer pelo Estado afirma a coexistência não problemática das comunidades, que 
ocupando o espaço público de uma certa visibilidade e reconhecimento, não deve nunca ser convertida numa diferenciação passível de quebrar um consenso valorativo. O espaço da diversidade organiza-se em torno das comunidades que o constituem e lhe dão a configuração específica (com formas particulares de se visibilizarem e de lhes ser outorgada visibilidade), configuração essa que, expressa na forma comunitária, corresponde a um consenso sobre as fronteiras grupais serem fundamentalmente recortadas pelo estatuto da nacionalidade. Embora surjam referências frequentes a características culturais específicas, o discurso da nacionalidade mantém bem presente essa ambiguidade latente, entre um estatuto abstrato, cujo horizonte é universal, e o seu contraste com a sociedade de acolhimento em que o nacional - do país de origem - surge narrado enquanto especificidade cultural. Assim, os brasileiros possuem características étnicas, tais como a música e o ritmo; os chineses estruturam as suas solidariedades "com base étnica" e os guineenses revelam uma "certa guineénidade"18. A "portuguesidade" dos portugueses é a única que abrange todas as outras: assume-se por conseguinte como verdadeira hiperidentificação cujo caráter passa justamente pela sua capacidade de abrigar uma multiplicidade cultural sem atritos e em perfeita coexistência. Enquanto hegemônica, desetniciza-se.

Disso mesmo são exemplo os editoriais da autoria de diversos altoscomissários, sobretudo desde que o Estado português, através do Alto Comissariado para a Imigração e Diálogo Intercultural (Acidi), definiu uma clara linha intercultural. Em torno deste discurso, constrói-se outro, que lhe serve de sustentáculo e que insiste em salientar uma matriz histórica específica, de cordialidade e absorção ${ }^{19}$. Esta matriz está particularmente presente nos agentes do Estado, menos nas associações, e reflete o peso que uma certa versão da história tem na elaboração da identidade nacional. Embora um discurso fortemente marcado por ela não esteja tão presente na narrativa portuguesa como na brasileira analisada anteriormente, a sua especificidade ganha significado quando observada a recorrência da invocação de uma matriz histórica particularizada, onde a metáfora da cordialidade recupera alguns dos tropos do discurso lusotropical. É assim que diante de uma vergonha social e política transversal à sociedade portuguesa em mencionar termos conotados com a última fase do colonialismo, tais como hibridismo ou miscigenação, se imiscui uma narrativa da história que recorre precisamente às mesmas interpretações. Nas palavras de um alto-comissário: “(...) essa diversidade sempre fez parte do ADN português quan- 


\section{Nuno Oliveira}

do partiu pelo mundo fora e se miscigenou com outros povos ${ }^{\prime 20}$. Os exemplos são múltiplos e constituem um dos eixos estruturantes do discurso oficial sobre a integração dos imigrantes ${ }^{21}$.

Contudo, o recurso ao discurso de pendor nacionalista, genésico e celebratório só excepcionalmente faz parte dos discursos dos representantes das comunidades imigrantes: mesmo as oriundas do espaço lusófono não recorrem a este quadro, optando por sublinhar a natureza intercultural presente. Seja como for, essa horizontalização cultural que o interculturalismo implica é a outra face de uma despolitização ativa que recorta o campo de ação das associações enquanto necessariamente cultural. Do ponto de vista de uma interculturalidade crítica, esta interculturalidade estatizada não promove a "transformação de estruturas e instituições que posicionam diferencialmente grupos, práticas e pensamentos dentro de uma ordem que é racial, ocidental e colonial" (Walsh, 2010).

\section{DUAS LÓGICAS DE GESTÃO SOCIAL DOS COLETIVOS}

Nesta conclusão propomos a ideia segundo a qual assistimos a duas tendências na gestão da diversidade etnocultural com diretas implicações na forma como as identidades coletivas são construídas e negociadas. Sugiro fazê-lo num sistema de oposições binárias que rejeita sequências teleológicas de aproximação à normatividade do Estado-nação incorporador, à maneira da tríade assimilação-multiculturalismo-interculturalidade, antes definindo grandes linhas de divergência entre soluções organizacionais e de institucionalização adotadas. A premissa considera a construção de identidades coletivas e das suas fronteiras um problema fundamental das sociedades humanas cuja análise deve passar pelas componentes culturais, simbólicas e institucionais: quem são os promulgadores de uma dada ordem social, dos seus códigos de distinção entre quem pertence e quem não pertence, em articulação com o controle da produção e distribuição de recursos, com a regulação do poder e do acesso a esses recursos (Eisenstadt, 2003:85). Com a brevidade que este espaço nos permite, procuramos analisar numa perspectiva historicizante dois trajetos que, emergindo de uma mesma narrativa pública, encontraram soluções diferenciadas de institucionalização e simbolização. Nestes processos, seguindo mais uma vez Eisenstadt, prestamos particular atenção ao papel das elites enquanto promulgadoras de visões e das codificações de perten- 
ça. Finalizamos por enumerar aqueles que se nos afiguram os aspectos essenciais destes processos de mudança social.

a) O processo em Portugal sugere uma tendência de desetnicização enquanto no Brasil assistimos a uma reetnicização. Portugal espelha quanto a nós uma tendência europeia que ausculta na "consciência étnica" o resultado da estigmatização ou do fechamento. $\mathrm{O}$ caso brasileiro mostra que a "consciência étnica" é um posicionamento na esfera pública no sentido da ressignificação e reposicionamento simbólico de uma identidade outrora subalternizada. $\mathrm{O}$ exemplo mais concreto é o reconhecimento das comunidades quilombolas com a sua procura de raízes étnicas e raciais originais. Podemos ainda acrescentar a disseminação de codificações raciais ou étnicas nas gramáticas institucionais.

b) Ao nível da codificação das pertenças, temos por um lado uma insistência nas múltiplas adesões identitárias (fragmentação das posições de sujeito) e nas suas propriedades intercambiáveis sugerida pela retórica intercultural em Portugal. Em contraste, no Brasil o discurso institucional formal e político prefigura um deslocamento de categorias abertas e intercambiáveis para definições coletivas assertivas. A adesão a identidades coletivas com características primordiais - ou de adesões subjetivas a categorias primordiais - parece ser um dos efeitos da política de pertença aos grupos de cor no Brasil atual. Neste quadro, os particularismos ganham destaque na esfera pública enquanto mediadores de reivindicações emancipatórias. Estes visam a extensão dos mecanismos políticos e legais de forma a acomodarem outras (novas) categorias político-identitárias. No sentido oposto, a incidência portuguesa na interculturalidade expressa um desejo de fusão, de sincretismo cultural, que não dote as identificações etnonacionais de um caráter político.

c) A politização das identidades tem vindo a traduzir-se na coletivização dos direitos (numa lógica de cidadania diferenciada), tais como as medidas de ação positiva que vão se disseminando pela estrutura institucional no Brasil contemporâneo. A estas contrapõe-se uma tendência crescente para a individualização dos direitos (cidadania liberal) em Portugal, sustentada na ideia da substituição necessária de identificações "fortes" por adesões cívicas de natureza individualizada. 


\section{Nuno Oliveira}

d) À problematização e relocalização das fronteiras étnicas e raciais resultantes da destituição das anteriores hierarquias e atribuições sociais da cor ou etnia no contexto brasileiro, contrapõe-se uma lógica social de diluição das fronteiras étnicas no sentido de uma horizontalização culturalizada, no caso português. Se a última se ancora na culturalização das relações entre grupos e das trocas com o Estado, a primeira se sustenta na distribuição social de recursos e poder nas relações entre grupos e nas trocas com o Estado.

A discussão desencadeada pela polêmica das cotas para negros que ocupou o espaço público brasileiro suscitou um conjunto de reações que evidenciaram a fragilidade de uma narrativa nacional em muito ainda baseada nos ideais da "democracia racial" e sua natureza inclusiva. Não era apenas o racismo que estava em pauta, mas antes as fronteiras coletivas e o seu lugar estrutural na sociedade mais alargada. Tendo em conta que o ponto de partida foi para ambos os contextos a retórica lusotropical, essa é uma discussão que ainda se encontra por fazer em Portugal.

(Recebido para publicação em fevereiro de 2014)

(Aprovado para publicação em maio de 2015) 


\section{Identificações Coletivas e Gestão da Diversidade Étnico-Cultural}

\section{NOTAS}

1. Esta visão encontra-se bem expressa em Freyre (1945).

2. A expressão é retirada de um opúsculo que reproduz uma intervenção do então ministro do Ultramar: Politique d'Integration, discurso pronunciado pelo ministro das províncias ultramarinas, professor Adriano Moreira na Associação Comercial do Porto.

3. Concluía assim, na sua qualidade de ministro da Presidência do governo português, na sessão de abertura do $30^{\circ}$ Conclave do Instituto Internacional de Civilizações Diferentes, realizado em Lisboa a 15 de abril de 1957, que a tese segundo a qual os portugueses se encontravam como agentes criadores de uma nova civilização dos trópicos era facilmente sustentável, porquanto o Estado português seria "um Estado pluriétnico, sem minorias nem maiorias, numa sociedade onde à tendência de assimilação dos povos tropicais corresponde o desejo de adaptação dos europeus". Caetano é citado em Freyre (1960).

4. Note-se, contudo, que o sentido atribuído ao conceito é de natureza legalista, entendendo por tal a igualdade de todos perante a lei e diferenciando-se assim a sua aplicação retórica do enunciado original de Freyre. Ver Nogueira (1965).

5. Ver, entre outros, Costa (1934) em comparação com Andrade (1968). Note-se que uma versão anterior tinha sido publicada em 1954 em inglês com o título Many Races one Sole Nation: The Tradicional Anti-Racialism of Portugal's Civilizing Methods (tradução de um original português de 1953). É evidente a substituição de uma narrativa veementemente imperial por uma insistência no caráter plurirracial e ecumênico da nação portuguesa, mantendo como eixo imperturbável um forte pendor nacionalista.

6. Exemplo de defensores desta última são os nomes que se reúnem em torno da revista Ultramar e que irão persistententemente defender a vocação colonizadora de Portugal. Textos da autoria de Óscar Soares Barata, Silva Rego, Oliveira e Castro, António Brásio e Luís Arnaut Pombeiro, seu diretor, reiteram incessantemente a especificidade portuguesa enquanto nação particularmente talhada para a árdua tarefa que é colonizar. Ver os textos da revista Ultramar, especialmente Barata (1961), Rego (1961) e Oliveira e Castro (1961).

7. Ver Cooper, para uma definição de Império: “(...) uma unidade política que é extensa, expansionista (ou tendo memórias de um passado expansionista) e que reproduz a diferenciação e a desigualdade entre as pessoas que incorpora" (2005:27, tradução livre).

8. Segundo a definição de Santos, estes seriam "lugares comuns retóricos mais abrangentes de determinada cultura que funcionam como premissas de argumentação que, por sua evidência, não se discutem" (2009:10-18).

9. A influência adviria, no plano antropológico, da parte de Roquette-Pinto, e no plano político social, da parte de Oliveira Lima, como bem ilustrado em Pallares-Burke (2005) e Gomes (2004).

10. Araújo (1994:31), nota justamente que a raça continua a ser central em Casa Grande e Senzala, e que em nenhum momento é completamente posta de lado em favor de uma abordagem somente cultural.

11. Informação fornecida pela Direção de Serviços de Estatística da Educação diretamente ao autor. 


\section{Nuno Oliveira}

12. Salienta Carlinda Leite que nos finais dos anos 1980 e 1990 eclodiu um discurso orientado para "a compreensão do fenômeno do multiculturalismo, quer para uma intervenção educativa que (...) respondesse às características plurais da população escolar", e insere esta orientação numa tendência mais ampla de criação da base institucional de um programa de "educação para todos" contido na Reforma Educativa iniciada com o XI Governo Constitucional. Ver Leite (2002:288).

13. Em uma comunicação de 2004, intitulada "O Regresso das Caravelas e a Missão ao Serviço do Acolhimento", no subcapítulo "Portugal Multicultural e Acolhedor", afirma-se peremptoriamente que "O multiculturalismo é a via que defendemos para Portugal". "O Regresso das Caravelas e a Missão ao Serviço do Acolhimento na Europa“, apresentada nas Jornadas Missionárias Nacionais de 2004.

14. Faro Declaration on the Council of Europe's Strategy for Developing Intercultural Dialogue. Intercultural Dialogue: The Way Ahead. Conferência de encerramento do 50으 aniversário da European Cultural Convention, realizada em 27-28 de outubro, Faro, Portugal.

15. Resolução do Conselho de Ministros no 63/2007, de 3 de maio.

16. Ver Secretaria de Direitos Humanos da Presidência da República (2010).

17. A monitorização étnica consiste em aferir as desigualdades entre as diferentes minorias étnicas relativamente à maioria, e tem sido aplicada com assinalável sistematicidade pelas autoridades locais na Inglaterra (Cantle, 2005:43-44). Quando constatadas diferenças sociais entre os grupos, tais como notórias discrepâncias na empregabilidade, no acesso à habitação, ou na sua representatividade na administração pública, medidas de ação positiva foram avançadas (ibidem:45).

18. A expressão é utilizada por um representante associativo em Oliveira (2012).

19. Nas palavras do Secretário de Estado Adjunto do Ministro-Adjunto e dos Assuntos Parlamentares, Feliciano Barreiras Duarte, "Fiéis à nossa história de povo que, ao longo da sua já longa caminhada de nove séculos sempre soube cruzar relacionamentos com outros povos, outras culturas, outras civilizações (...) que nos transformam enquanto povo na nossa genética e na nossa maneira de ser e de estar no mundo" (Duarte, 2012).

20. Retirado do editorial do B-i "Portugal e a Diversidade. Um País em Transformação?". Segundo um anterior alto-comissário para a imigração, a história portuguesa estaria "cheia de exemplos de experiências interculturais (...) ao nível da própria demografia, ao nível do ADN, se quisermos, há muitas experiências interculturais que fazem parte da identidade portuguesa. (...) quando se fala de Portugal e da sua identidade ela é por si mesmo uma identidade intercultural" (Oliveira, 2012:205).

21. Os trabalhos de Manuela Ribeiro Sanches destacam-se pela crítica insistente a uma normalização deste discurso e à sua presença acrítica na esfera pública. Diz a autora em Malhas que os Impérios Tecem: “Importa também estimular um debate no nosso país, questionando consensos pouco produtivos, tais como a 'colonização exemplar portuguesa', a nossa proverbial 'tolerância' e 'mestiçagem', chamando, ao mesmo tempo, a atenção para as razões que assistiram e inspiraram a violência mais ou menos acentuada do anticolonial" (Sanches, 2011:12). 


\section{Identificações Coletivas e Gestão da Diversidade Étnico-Cultural}

\section{REFERÊNCIAS BIBLIOGRÁFICAS}

ALEXANDRE, Valentim. (1993), "Ideologia, Economia e Política: A Questão Colonial na Implantação do Estado Novo”. Análise Social, vol. XXVIII, noㅡ 123-124, pp. 1117-1136.

(1998), "Nação e Império", in F. Bethencourt; K. Chaudhuri (orgs.), História da Expansão Portuguesa. Lisboa, Círculo de Leitores, pp.10-45.

ALMEIDA, Miguel Vale de. (2000), Um Mar da Cor da Terra: Raça, Cultura e Política da Identidade. Oeiras, Celta.

ANDRADE, António Alberto B. de. (1968), Muitas Raças, uma Só Nação: Esboço da Teoria do Humanismo Português. Lisboa, Agência-Geral do Ultramar.

ANDRADE, Mário Pinto de [Buanga Fele]. (1955), “Qu'est-ce que le 'Luso Tropicalismo'?". Présence Africaine, no 4, pp. 24-35.

ARAÚJO, Ricardo Benzaquen de. (1994), Guerra e Paz: Casa-Grande e Senzala e a Obra de Gilberto Freyre nos Anos 30. São Paulo, Editora 34.

BARATA, Oscar Soares. (1961), "O Sentido Humano do Pluri-racialismo Português". Ultramar, no 5, pp.18-28.

BARTH, Fredrik (ed.). (1976), Los Grupos Étnicos y sus Fronteras. La Organización Social de las Diferencias Culturales. Introducción. México, Fondo de Cultura Económica.

BAUBÖCK, Rainer. (1994), Transnational Citizenship: Membership and Rights in International Migration. Cheltenham, Edward Elgar Publishing.

BRUBAKER, Rogers. (1992), Citizenship and Nationhood in France and Germany. Cambridge, Harvard University Press.

. (2004), Ethnicity without Groups. Cambridge, Harvard University Press.

CANTLE, Ted. (2005), Community Cohesion. A New Framework for Race and Diversity. London, Palgrave Macmillan.

CARDOSO, Fernando Henrique. (1962), Capitalismo e Escravidão no Brasil Meridional: O Negro na Sociedade Escravocrata no Rio Grande do Sul. São Paulo, Difusão Europeia do Livro.

CARNEIRO, Roberto. (1997), "Construção da Europa: Contributos e Limites das Políticas Educativas" , in Conselho Nacional de Educação, Política Educativa: Construção da Europa e Identidade Nacional. Actas da Conferência do Conselho Nacional de Educação. Lisboa, Editorial do Ministério da Educação, pp. 72-85.

CASTELO, Cláudia. (1998), O Modo Português de Estar no Mundo: O Lusotropicalismo e a Ideologia Colonial Portuguesa (1933-1961). Porto, Afrontamento.

(2007), Passagens para África: O Povoamento de Angola e Moçambique com Naturais da Metrópole (1920-1974). Porto, Afrontamento.

(2011), Scientific Research, Political Power and the Empire in the Decolonisation Era. Trabalho apresentado na Conferência Internacional The End of Portuguese Empire in a Comparative Perspective, Instituto de Ciências Sociais/Universidade de Lisboa, 20-21 de junho.

COHEN, Anthony P. (1985), The Symbolic Construction of Community. London, Routledge.

DADOS - Revista de Ciências Sociais, Rio de Janeiro, vol. 58, nº 4, 2015 


\section{Nuno Oliveira}

CONCEIÇÃO NETO, Maria da. (1997), "Ideologias, Contradições e Mistificações da Colonização de Angola no Século XX". Lusotopie. Paris, Éditions Karthala, pp. 327-359.

COOPER, Frederick. (2005), Colonialism in Question: Theory, Knowledge, History. Berkeley, University of California Press.

COSTA, Augusto da. (1934), Apologia do Império Português. Lisboa, Imprensa Nacional.

COSTA, Emília Viotti da. (1966), Da Senzala à Colônia. São Paulo, Difel.

COSTA, Sérgio. (2006), Os Dois Atlânticos: Teoria Social, Antirracismo, Cosmopolitismo. Belo Horizonte, UFMG Editora.

DEGLER, Carl N. (1971), Neither Blacknor White: Slavery and Race Relations in Brazil and the United States. New York, Macmillan.

DUARTE, Feliciano Barreiras. (2012), “Portugal e a Diversidade. Um País em Transformação?". B-i [boletim informativo], no 93, Acidi, pp. 3.

EISENSTADT, Shmuel N. (2003), Comparative Civilizations and Multiple Modernities (Part I). Leiden, Brill.

EMIRBAYER, Mustafa. (1997), "Manifesto for a Relational Sociology". American Journal of Sociology, vol. 103, no 2, pp. 281-318.

FASSIN, Didier; SIMON, Patrick. (2008), “Un Objet sans Nom: L’Introduction des Discriminations Raciales dans la Statistique Française". L'Homme, no 187-188, pp. 271-294.

FERNANDES, Florestan. (1965), A Integração do Negro na Sociedade de Classes (vol. I e II). São Paulo, Dominus Editora.

FREYRE, Gilberto. (1945), Brazil: An Interpretation. New York, Alfred A. Knoff.

. (1950) [1933], Casa Grande \& Senzala. Introdução à História da Sociedade Patriarcal no Brasil (vol. I). São Paulo, José Olympio Editora.

. (1960), "A Antropologia Brasileira num Conclave Internacional de Sábios", in Brasis, Brasil e Brasília. Lisboa, Livros do Brasil, p. 42.

. (2004) [1936], Sobrados e Mucambos. Decadência do Patriarcado Rural e Desenvolvimento do Urbano. (15a ed.). São Paulo, Global Editora.

GOMES, Ângela de Castro. (1997), “L’Histoire du Brésil Écrite par l’Estado Novo: Démocratie Raciale contre Démocratie Libérale". Lusotopie, pp. 267-273.

. (2004), “Em Família: A Correspondência entre Oliveira Lima e Gilberto Freyre”, in A. de C. Gomes (org.), Escrita de Si, Escrita da História. Rio de Janeiro, FGV Editora, pp. 51-76.

GORENDER, Jacob. (1988), O Escravismo Colonial. (5a ed.). São Paulo, Ática.

GUIMARÃES, Antonio S. (2003), “Démocratie Raciale". Cahiers du Brésil Contemporaine, no 49/50, pp. 11-38.

. (2009), "Aprés la Démocratie Raciale", in S. C. Almeida; A. Fléchet (eds.), De la Démocratie Raciale au Multiculturalisme. Brésil, Amériques, Europe. Bruxeles, Peter Lang, pp.133-152.

HENRIQUES, Isabel Castro. (2004), Os Pilares da Diferença: Relações Portugal-África: Séculos XV-XX. Lisboa, Caleidoscópio. 


\section{Identificações Coletivas e Gestão da Diversidade Étnico-Cultural}

HENTSCHKE, Jens R. (ed.). (2006), Vargas and Brazil: New Perspectives. New York, Palgrave MacMillan.

IANNI, Octavio. (1972), Raça e Classes Sociais no Brasil. Rio de Janeiro, Civilização Brasileira.

LAMONT, Michèlle; MOLNÁR, Virág. (2002), “The Study of Boundaries in the Social Sciences". Annual Review of Sociology, vol. 28, pp. 167-195.

LEITE, Carlinda. (2002), O Currículo e o Multiculturalismo no Sistema Educativo Português. Lisboa, Fundação Calouste Goulbenkian.

LEONARD, Yves. (1999), “O Ultramar Português”, in F. Bethencourt; K. Chauduri (eds.), História da Expansão Portuguesa. Lisboa, Círculo de Leitores, vol. 5, pp. 30-50.

MATOS, Patrícia Ferraz de. (2006), As Côres do Império. Representações Raciais no Império Colonial Português. Lisboa, ICS.

MATTOS, Hebe. (2000), Escravidão e Cidadania no Brasil Monárquico. Rio de Janeiro, Jorge Zahar Editor.

MEDINA, João. (2000), “Gilberto Freyre Contestado: O Lusotropicalismo Criticado nas Colónias Portuguesas como Alibi Colonial do Salazarismo". Revista USP, no 45, pp. 48-61.

MUNCH, Richard. (2001), Nations and Citizenship in a Global Age. From National to Transnational Ties and Identities. London, Palgrave Macmillan.

NOGUEIRA, Franco. (1965), Política Externa Portuguesa. Lisboa, Ministério dos Negócios Estrangeiros.

OLIVEIRA, Nuno. (2001), Portugal: País de Imigração. A Política de um Imaginário. Dissertação (Mestrado em Economia e Sociologia Históricas), Universidade Nova de Lisboa, Lisboa.

. (2012), Políticas de Categorização Étnica: Portugal e o Brasil em Perspectiva Comparada. Tese (Doutorado em Sociologia), Instituto Universitário de Lisboa, Lisboa.

OLIVEIRA E CASTRO, Luís Filipe de. (1961), "Conceito Português de Colonização". Ultramar, no 5, pp. 29-42.

PALLARES-BURKE, Maria. (2005), Gilberto Freyre: Um Vitoriano nos Trópicos. São Paulo, Editora Unesp.

PIETERSE, Ian Nederveen. (2007), Ethnicities and Global Multiculture: Pants for an Octopus. Maryland, Rowman \& Littlefield Publishers.

PINTO, João Alberto da Costa. (2009), “Gilberto Freyre e a Intelligentsia Salazarista em Defesa do Império Colonial Português (1951-1974)”. História, vol. 28, no 1, pp. $445-482$.

PIRES, Rui Pena. (2003), Migrações e Integração. Oeiras, Celta Editora.

REGO, A. da Silva. (1961), "A Cor Barreira, Argumento e Arma: Ensaios e Estudos". Ultramar, no 5, pp. 9-17.

RIBEIRO, Darcy. (1995), O Povo Brasileiro: A Formação e o Sentido do Brasil. São Paulo, Companhia das Letras.

DADOS - Revista de Ciências Sociais, Rio de Janeiro, vol. 58, n 4, 2015 


\section{Nuno Oliveira}

RUSSELL-WOOD, Anthony John. (1982), The Black Man in Slavery and Freedom in Colonial Brazil. New York, Palgrave Macmillan.

SANCHES, Manuela Ribeiro (org.). (2011), Malhas que os Impérios Tecem: Textos Anticoloniais, Contextos Pós-coloniais. Lisboa, Edições 70.

SANTOS, Boaventura de Sousa. (2009), "Direitos Humanos: O Desafio da Interculturalidade". Revista Direitos Humanos, no 2, pp. 10-18.

SCHWARCZ, Lilia Moritz. (1993), O Espetáculo das Raças. Cientistas, Instituições e Questão Racial no Brasil, 1870-1930. São Paulo, Companhia das Letras.

SECRETARIA DE DIREITOS HUMANOS DA PRESIDÊNCIA DA REPÚBLICA. (2010), Programa Nacional de Direitos Humanos (rev. e atual.). Brasília, SDH/Pr, pp. 196-197.

SEWELL JR., William H. (1992), “A Theory of Structure: Duality, Agency, and Transformation". American Journal of Sociology, vol. 98, no 1, pp.1-29.

SKIDMORE, Thomas. (1989) [1976], Preto no Branco. Raça e Nacionalidade no Pensamento Brasileiro. Rio de Janeiro, Paz e Terra.

SOMERS, Margaret R. (1994), "The Narrative Constitution of Identity. A Relational and Network Approach". Theory and Society, vol. 23, no 5, pp. 605-649.

. (1996), "Where is Sociology after the Historic Turn? Knowledge Cultures, Narrativity, and Historical Epistemologies", in T. J. McDonald (ed.), The Historic Turn in the Human Sciences. Ann Arbor, University of Michigan Press, pp. 53-90.

SOYSAL, Yasemin. (1994), Limits of Citizenship. Migrants and Postnational Membership in Europe. Chicago, The University of Chicago Press.

THOMAZ, Omar Ribeiro. (2007), “Tigres de Papel: Gilberto Freyre, Portugal e os Países Africanos de Língua Oficial Portuguesa", in C. Bastos; M. Almeida; B. FeldmanBianco (orgs.), Trânsitos Coloniais: Diálogos Críticos Luso-brasileiros. Campinas, Editora Unicamp.

UITERMARK, Justus. (2012), Dynamics of Power in Dutch Integration Politics. From Accommodation to Confrontation. Amsterdam, University of Amsterdam Press.

WALSH, Catherine. (2010), "Interculturalidad Crítica y Educación Intercultural”, in J. Viaña; L. Tapia; C. Walsh (orgs.), Construyendo Interculturalidad Crítica. La Paz, Instituto Internacional de Integración del Convenio Andrés Bello, pp. 75-96. 


\section{RESUMO \\ Identificações Coletivas e Gestão da Diversidade Étnico-cultural: Dinâmicas Sociais Contrastantes entre Portugal e o Brasil}

Neste artigo são utilizados os conceitos de identidade narrativa e configuração relacional para compreender as diferentes formas como os Estados organizam os reconhecimentos coletivos e as suas gramáticas institucionais. Usando a narrativa como ferramenta analítica procuramos mostrar como as identidades coletivas são construídas historicamente salientando simultaneamente a imbricação de narrativas de diversos níveis institucionais para legitimar as concepções coletivas de fronteiras identitárias. Metodologicamente, o texto se baseia em uma abordagem historicizante que se vale de fontes secundárias e de pesquisa de um corpus selecionado de documentos oficiais resultante de trabalho de campo em Portugal e no Brasil. Sugerimos que a comparação entre estes contextos permite perceber movimentos divergentes em matéria de concepção das adesões coletivas e dos seus significados em face do pluralismo cívico e étnico-cultural do Estado-nação contemporâneo.

Palavras-chave: identificações coletivas; fronteiras simbólicas; lusotropicalismo; interculturalidade; multiculturalismo

\section{ABSTRACT \\ Collective Identifications and the Management of Ethnic-cultural Diversity: Contrasting Social Dynamics between Brazil and Portugal}

In this article we employ the concepts of narrative identity and relational configuration in order to understand the different forms how States organize collective recognition and their institutional grammars. Using narrative as an analytical tool, we seek to show how collective identities are constructed historically, emphasizing simultaneously the intertwining of narratives of different institutional levels to legitimize the collective conceptions of frontiers of identities. Methodologically, the text is based on a historicizing approach that employs secondary sources and a research of a selected corpus of official documents collected in fieldwork in Portugal and Brazil. We suggest that the comparison between these contexts allows perceiving diverging movements in terms of the conception of collective adhesions and their meanings in the context of civic and ethnic-cultural pluralism in the contemporary nation-state.

Keywords: collective identities; symbolical frontiers; lusotropicalismo; interculturality; multiculturalism 


\section{Nuno Oliveira}

\section{RÉSUMÉ}

Identifications Collectives et Gestion de la Diversité Ethnico-culturelle: Dynamiques Sociales en Contrastes au Portugal et au Brésil

Nous ferons ici appel aux concepts d'identité narrative et de configuration relationnelle pour comprendre les différentes manières selon lesquelles les États organisent les reconnaissances collectives et leurs grammaires institutionnelles. En utilisant le récit comme un outil analytique, nous cherchons à montrer comment les identités collectives sont historiquement construites grâce à une imbrication simultanée de récits de différents niveaux institutionnels visant la légitimation de conceptions collectives des frontières identitaires. Au niveau méthodologique, le texte se base sur une approche historicisante faisant usage de sources secondaires et d'un corpus de documents officiels sélectionnés suite à un travail de terrain au Portugal et au Brésil. Nous suggérons que la comparaison entre ces contextes permet de percevoir des mouvements divergents en matière de conception des adhésions collectives et de leurs significations face au pluralisme civique et ethnico-culturel de l'État-nation contemporain.

Mots-clés: identifications collectives; frontières symboliques; luso-tropicalisme; interculturalité; multiculturalisme

\section{RESUMEN}

Identificaciones Colectivas y Gestión de la Diversidad Étnico-cultural: Dinámicas Sociales Contrastantes entre Brasil e Portugal

En este artículo son utilizados los conceptos de identidad narrativa y configuración relacional para comprender las diferentes formas a través de las cuales los Estados organizan sus reconocimientos colectivos y sus gramáticas institucionales. Usando la narrativa como herramienta analítica se busca mostrar cómo las identidades colectivas son construidas históricamente subrayando la imbricación de narrativas de diversos niveles institucionales para legitimar las concepciones colectivas de fronteras identitarias. En términos metodológicos, el texto se base en una aproximación historicizante a partir de fuentes secundarias y de un corpus seleccionado de documentos oficiales resultante de trabajo de campo en Portugal y en Brasil. Finalmente, se propone que la comparación entre estos contextos permite percibir movimientos divergentes en materia de concepción de las adhesiones colectivas y sus significados frente al pluralismo cívico y étnico-cultura del Estado-nación contemporáneo.

Palabras clave: identificaciones colectivas; fronteras simbólicas; lusotropicalismo; interculturalidad; multiculturalismo 